Supporting Information

\title{
In situ Crosslinking of Artificial Basement Membranes in 3D Tissues and Size-dependent Molecular Permeability
}

Jinfeng Zeng ${ }^{\dagger}$, Clara R. Correia ${ }^{\ddagger}$ João F. Mano ${ }^{\ddagger}$ and Michiya Matsusaki*†

†Department of Applied Chemistry, Graduate School of Engineering, Osaka University,

2-1 Yamadaoka, Suita, Osaka 565-0871, Japan.

E-mail: m-matsus@chem.eng.osaka-u.ac.jp

$\star$ Department of Chemistry, CICECO-Aveiro Institute of Materials, University of Aveiro, Campus Universitário de Santiago, 3810-193, Aveiro, Portugal.

\section{Contents:}

\section{Table S1}

Figure S1-S10 
Table S1. Parameters of model molecules measured in buffer solution $(\mathrm{pH}=7.4)$ at room temperature.

\begin{tabular}{ccccc}
\hline Model Molecules & $\begin{array}{c}\text { Concentration } \\
(\mathrm{mg} / \mathrm{mL})\end{array}$ & $\begin{array}{c}\text { Diameter }(\mathrm{nm}) \\
\text { Volume }\end{array}$ & PDI & $\begin{array}{c}\text { Zeta Potential } \\
(\mathrm{mv})\end{array}$ \\
\hline PS NPs $(530 \mathrm{~nm})$ & 1.0 & 531 & 0.03 & -47.2 \\
PS NPs $(250 \mathrm{~nm})$ & 1.0 & 396 & 0.26 & -30.3 \\
PS NPs $(40 \mathrm{~nm})$ & 1.0 & 37.8 & 0.08 & -67.6 \\
Dextran $(2,000 \mathrm{kDa})$ & 1.0 & 19.5 & 0.56 & -11.6 \\
Dextran $(230 \mathrm{kDa})$ & 1.0 & 10.1 & 0.35 & -12.5 \\
Dextran $(9.5 \mathrm{kDa})$ & 1.0 & 4.2 & 1.0 & -14.1 \\
Albumin & 1.0 & 7.4 & 0.10 & -20.2 \\
Col-IV & 1.0 & - & - & 0.2 \\
LM & 1.0 & - & - & -11.6 \\
\hline
\end{tabular}

PS NPs, dextran, albumin were evaluated in PBS buffer solution $(\mathrm{pH}=7.4)$, Col-IV and LM were evaluated in the Tris-HCl buffer solution ( $\mathrm{pH}=7.4)$. PS NPs were labeled with Nile red, dextran was modified by Fluorescein isothiocyanate (FITC) and Tetramethylrhodamine (TRITC) provided fluorescence signal for albumin. 


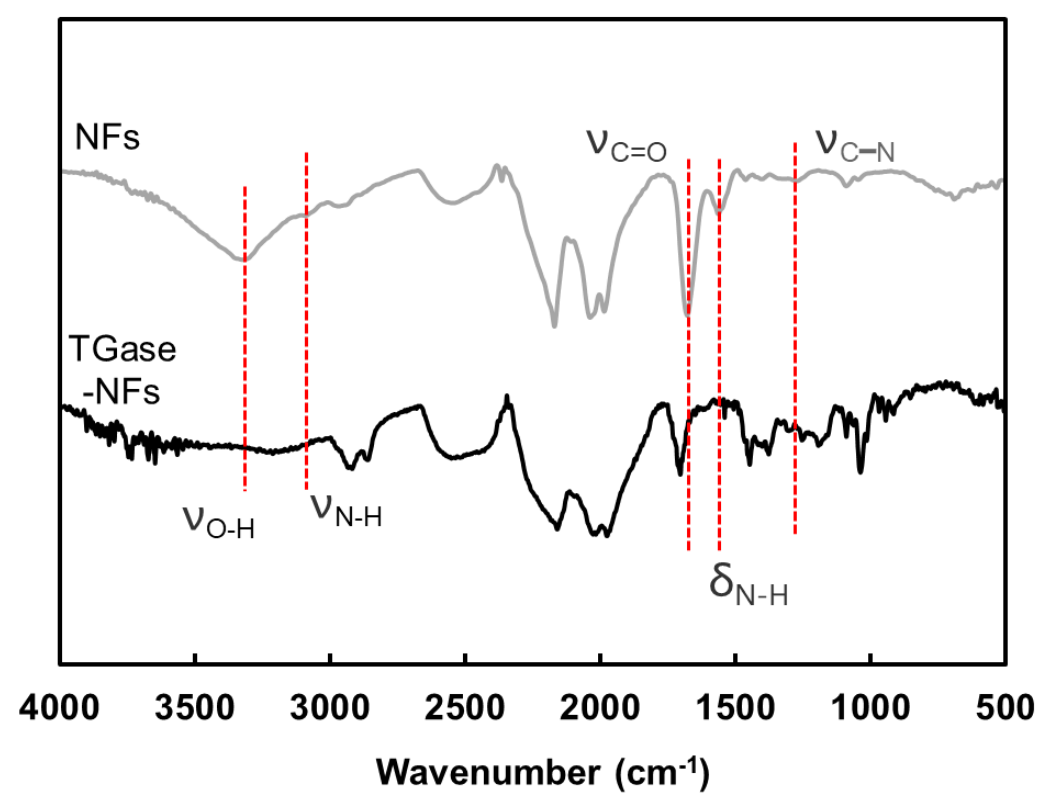

Figure S1. FT-IR spectra of (Col-IV/LM) $)_{5}$ nanofilms (NFs) and TGase crosslinked (ColIV/LM) 5 nanofilms (TGase-NFs, $2.0 \mathrm{U} / \mathrm{mL}$ of TGase for $2 \mathrm{~h}$ ). 




Figure S2. The permeability of Col-IV/LM nanofilms with different thicknesses to FITCdextran $(20 \mathrm{~nm}, 2,000 \mathrm{kDa})$ in the period of $24 \mathrm{~h}$ incubation at $37^{\circ} \mathrm{C}$. The thickness of nanofilms, namely $12,40,68,110$, or $137 \mathrm{~nm}$, was controlled by different assemble steps, $1-5$ bilayers, respectively. $n=3$. 




Figure S3. Percentage of penetrated, unpenetrated and absorbed albumin and Dextran-20 $\mathrm{nm}$ through $(\mathrm{Col}-\mathrm{IV} / \mathrm{LM})_{5}$ nanofilms, incubated at $37^{\circ} \mathrm{C}$ for $8 \mathrm{~h}$. 


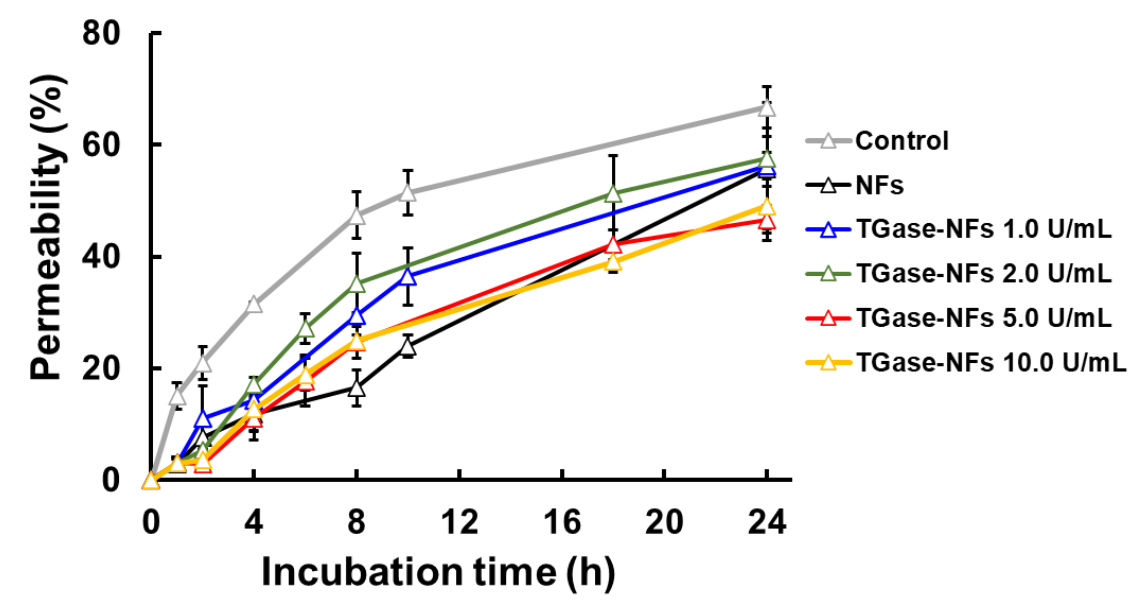

Figure S4. Permeability of $(\mathrm{Col}-\mathrm{IV} / \mathrm{LM})_{5}$ nanofilms crosslinked by various concentrations of TGase to TRITC-Albumin incubated at $37^{\circ} \mathrm{C}$ for $24 \mathrm{~h} . \mathrm{n}=3$. 
(a)
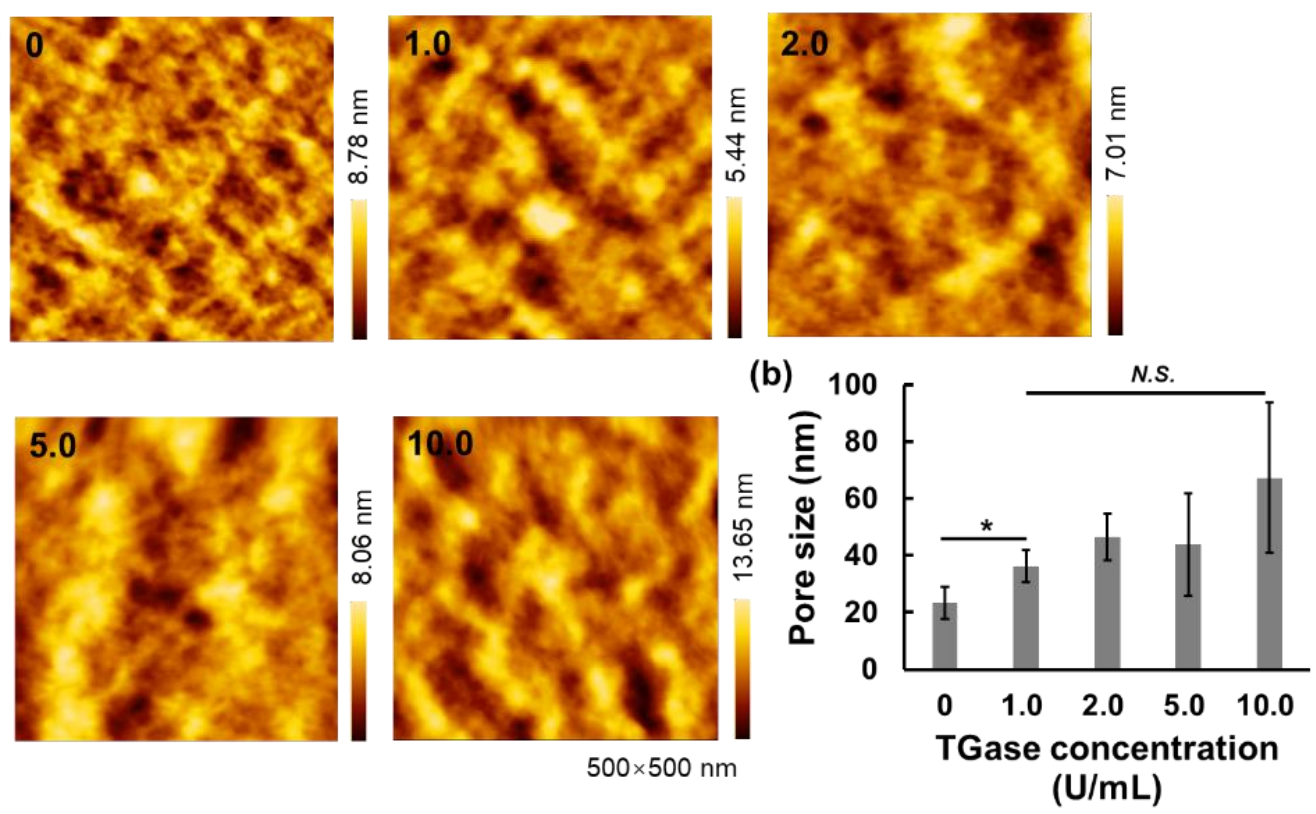

Figure S5. (a) AFM images $(500 \times 500 \mathrm{~nm})$ and (b) the pore sizes of TGase crosslinked $(\mathrm{Col}-\mathrm{IV} / \mathrm{LM})_{5}$ nanofilms on glass substrates. The concentrations of TGase were controlled at $0,1.0,2.0,5.0,10.0 \mathrm{U} / \mathrm{mL}$, and incubation time was $2 \mathrm{~h}$. 



Figure S6. CLSM images of (Col-IV/LM $)_{5}$ nanofilms with or without crosslinking prepared on NHDF layers $\left(1.0 \times 10^{6}\right)$ in the 24 -well insert. FAM-Col-IV and RhodamineLM whose concentrations were $40 \mu \mathrm{g} / \mathrm{mL}$, respectively, were used to show the morphology of assembled nanofilms. The crosslinked nanofilms was prepared by immersing the nanofilms in TGase $/ \mathrm{Ca}^{2+} /$ Tris- $\mathrm{HCl}$ solutions $(5.0 \mathrm{U} / \mathrm{mL}, \mathrm{pH}=7.4)$ at $37^{\circ} \mathrm{C}$ for $30 \mathrm{~min}$. Scale bar is $100 \mu \mathrm{m}$. 


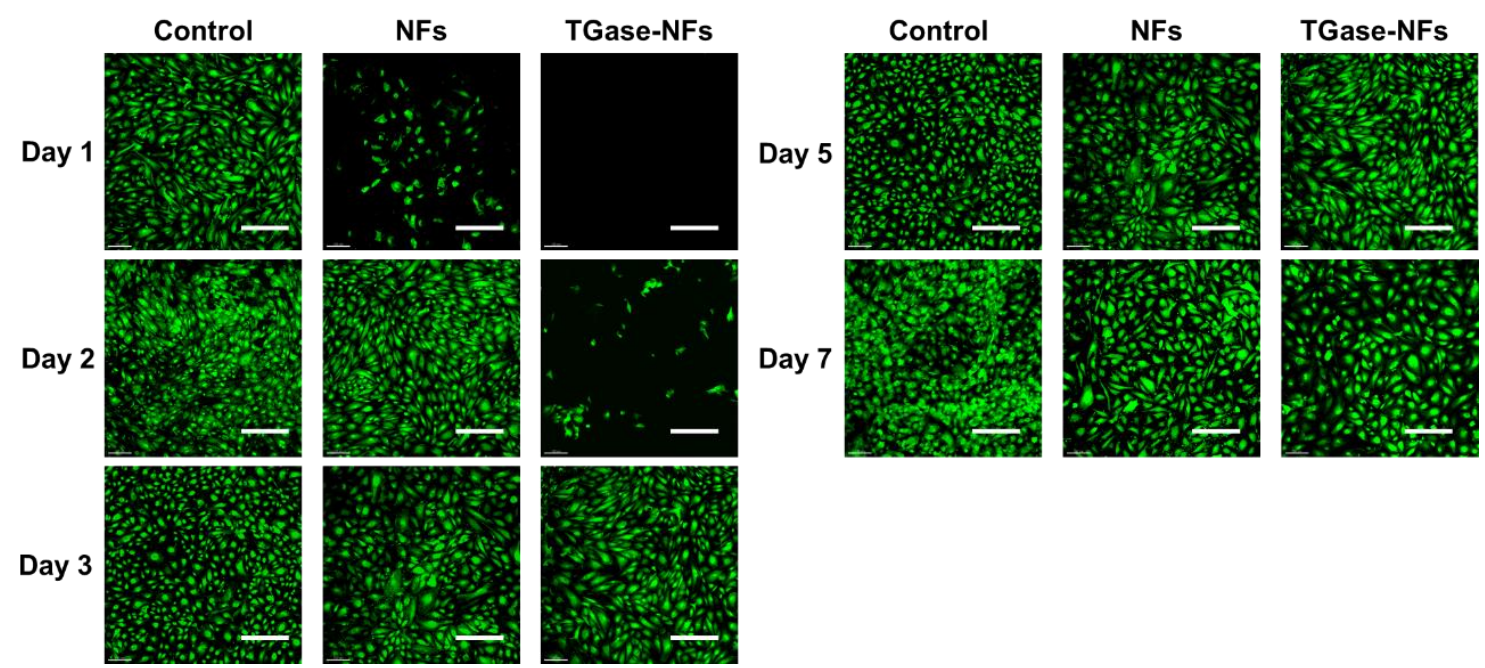

Figure S7. Fluorescence images of migrated HUVEC through 24-well transwell membrane (3.0 $\mu \mathrm{m}$ pores) coated with or without (control) nanofilms (NFs) after incubation for 7 days. Un-crosslinked (NFs) or TGase crosslinked (Col-IVLM) 5 (TGaseNFs) were used. TGase-NFs were prepared by immersing the nanofilms in TGase $/ \mathrm{Ca}^{2+} /$ Tris- $\mathrm{HCl}$ solutions at $2.0 \mathrm{U} / \mathrm{mL}$ for $2 \mathrm{~h}$. The scale bar is $300 \mu \mathrm{m}$. 


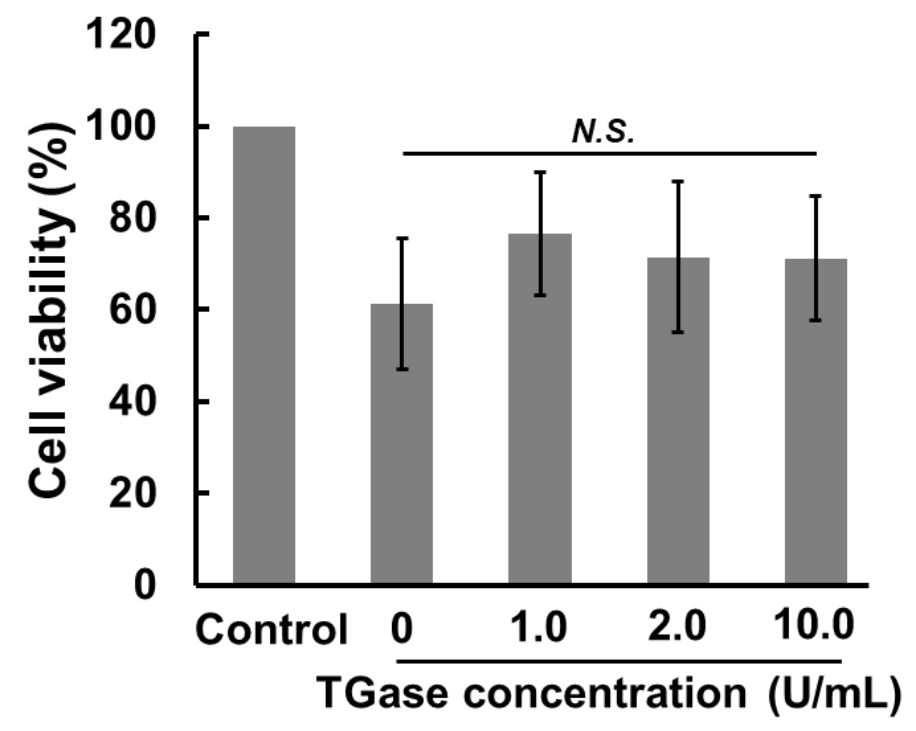

Figure S8. Cytotoxicity evaluation of $\mathrm{TGase} / \mathrm{Ca}^{2+} / \mathrm{Tris}-\mathrm{HCl}$ solution $(\mathrm{pH}=7.4)$ using WST-8 kit assay. NHDF were incubated with TGase/ $\mathrm{Ca}^{2+} /$ Tris- $\mathrm{HCl}$ solution $(\mathrm{pH}=7.4)$ for $2 \mathrm{~h}$ in the absence of cell culture medium. $\mathrm{n}=6$. 


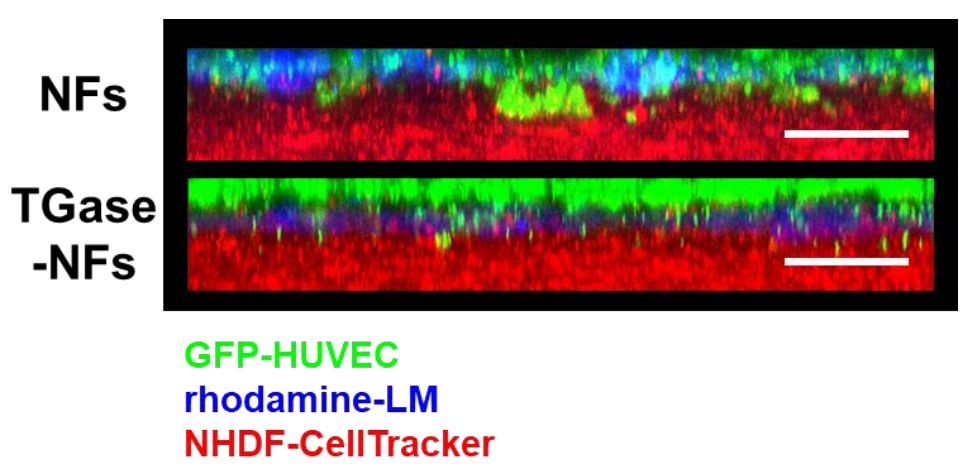

Figure S9. Cross-sectional CLSM images of relative positions of (Col-IV/LM)5 nanofilms (LM was labeled with rhodamine), GFP-HUVEC and NHDF (CellTracker ${ }^{\mathrm{TM}}$ Deep Red) after $24 \mathrm{~h}$ incubation. TGase-NFs were prepared by immersing the nanofilms in TGase $/ \mathrm{Ca}^{2+} / \mathrm{Tris}-\mathrm{HCl}$ solutions at $5.0 \mathrm{U} / \mathrm{mL}$ for $30 \mathrm{~min}$. The scale bar is $100 \mu \mathrm{m}$. 


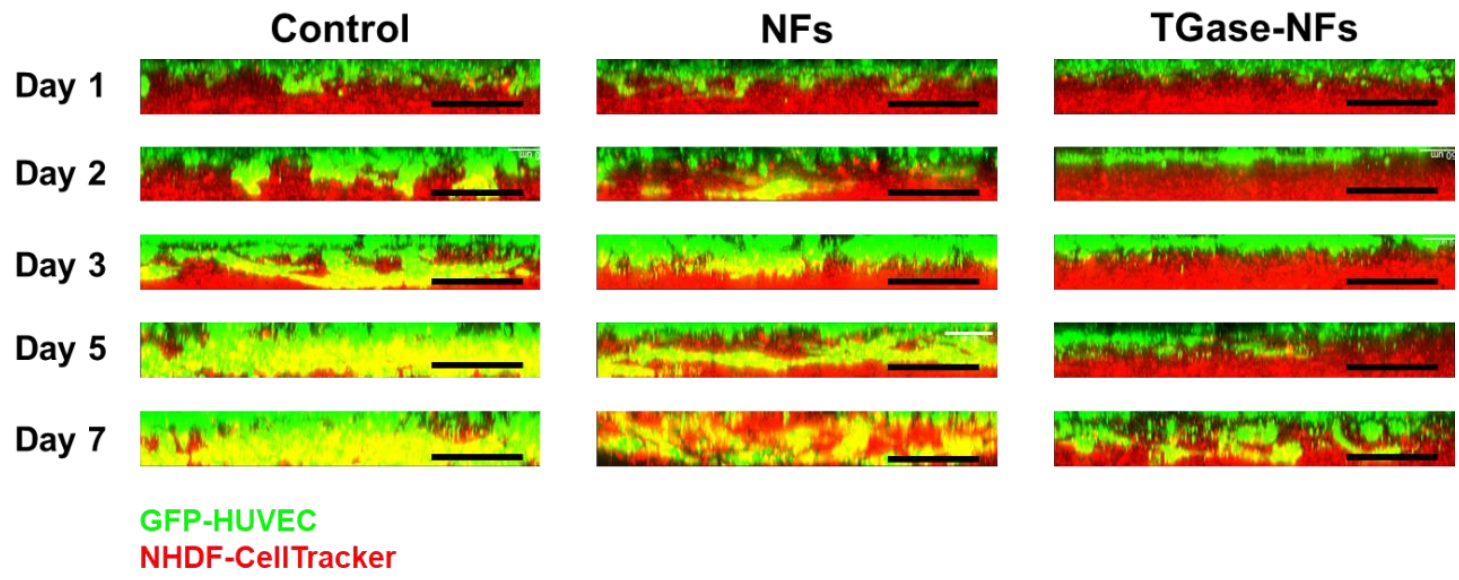

Figure S10. Cross-sectional CLSM images of patterned cells co-culture with or without the barrier effect of crosslinked (Col-IV/LM $)_{5}$ nanofilms. Comparison of the penetration of GFP-HUVEC through NHDF (stained by CellTracker ${ }^{\mathrm{TM}}$ Deep Red) layers after 7 days incubation. TGase-NFs were prepared by immersing the nanofilms in TGase/ $\mathrm{Ca}^{2+} / \mathrm{Tris}^{-}$ $\mathrm{HCl}$ solutions at $5.0 \mathrm{U} / \mathrm{mL}$ for $30 \mathrm{~min}$. The scale bar is $100 \mu \mathrm{m}$. 